\title{
Grafting Vinyl Monomers onto Chitosan:IV:Graft Copolymerized of Acrylicacid onto Chitosan Using Ceric Ammonium Nitrate as the Initiator- Characterization and Antimicrobial Activities
}

\author{
Manoj Kumar Pati, Padmalochan Nayak*
}

Research Foundation, Neelachal Bhavan, Cuttack, Odisha, India.

E-mail: "plnayak@rediffmail.com

Received October $20^{\text {th }}, 2011$; revised November $24^{\text {th }}, 2011$; accepted December $2^{\text {nd }}, 2011$.

\begin{abstract}
Acrylicacid was grafted onto chitosan by using the ceric ammonium nitrate as the initiator. The effect of initiator concentration, monomer concentration, time \& temperature on $\% G$ and $\% G E$ were studied. The grafted samples were characterized using FTIR, TGA, SEM and XRD methods. From the FTIR data it was ascertained that grafting has occurred considerably. The morphology of the grafted polymer was observed from the SEM picture. The thermal analysis indicated the different stages of degradation of the grafted copolymer. Evidence of grafting was obtained from comparison of SEM, XRD, and FTIR of the grafted and nongrafted chitosan as well as solubility characteristics of the products. The antibacterial and antifungal activities of the grafted polymer have also been investigated.
\end{abstract}

Keywords: Chitosan, Acrylicacid, Graftcopolymerization, Antifungal, Antibactarial

\section{Introduction}

Grafting vinyl monomers onto natural and synthetic polymers is a challenging field of research with unlimited future prospects. During the last four decades Nayak and co-workers have studies the graft copolymerization of several monomers onto a multitude of natural and synthetic polymers like wool, silk, cellulose, nylon and PET, rubber to enhance their properties using various initiators like hexavalent chromium, quinquevalent vanadium, tetravalent cerium, trivalent manganese, peroxydisulphate and peroxydiphophate ions [1-16].

Chitosan is a partially deacetylated polymer of acetyl glucosamine obtained after alkaline deacetylation of the chitin. It displays interesting properties such as biocompatibility, biodegradability [17-21] and its degradation products are non-toxic, non-immunogenic and non-carcinogenic [22-24]. Therefore, chitosan has prospective applications in many fields such as biomedicine, waste water treatment, functional membranes and flocculation. However, chitosan can only soluble in few dilute acid solutions, which limits its wide applications. Recently, there has been a growing interest in chemical modification of chitosan to improve its solubility and widen its applications [25-31]). Among various methods, graft copolymerization is most attractive because it is a useful technique for modifying the chemical and physical properties of natural polymers. Chitosan bears two types of reactive groups that can be grafted. First, the free amino groups on deacetylated units and secondly, the hydroxyl groups on the $\mathrm{C} 3$ and $\mathrm{C} 6$ carbons on acetylated or deacetylated units. Grafting of chitosan allows the formation of functional derivatives by covalent binding of a molecule, the graft, onto the chitosan backbone. Recently, researchers have also shown that after primary deviation followed by graft modification; chitosan would obtain much improved water solubility and bioactivities such as antibacterial and antioxidant properties [32]. Grafting chitosan is a common way to improve chitosan properties such as increasing chelating [33] or complexation properties [34), bacteriostatic effect [35] or enhancing adsorption properties [36,37]. Although the grafting of chitosan modifies its properties, it is possible to maintain some interesting characteristics such as mucoadhesivity [38], biocompatibility [39] and biodegradability [40]. Many investigations have been carried out on the graft copolymerization of chitosan in view of preparing poly- 
saccharide-based advanced materials with unique bioactivities and thus widening their applications in biomedicine and environmental fields. A few review articles on the potential applications of chitosan for pharmaceutical, veterinary medicine, biomedical and environmental field have already been reported [41-49]. However, there is no review available on the graft copolymerization of chitosan and its applications, despites the considerable amount of works have been published in this field. Moreover, the potential applications of grafted chitosan in the various fields such as drug delivery, biomedical, tissue engineering and environmental is also discussed.

In the present research program, we wish to report the graft copolymerization of Acrylicacid onto chitosan using ceric ammonium nitrate as the initiator. The graft copolymrization was studied by varying the initiator, time, temperature and concentration of monomer. The grafted polymers were characterized by SEM, XRD and FTIR studies. The antibacterial and antifungal activity of the grafted samples have been reported.

\section{Material and Method}

Chitosan with more than $95 \%$ deacylated was obtained as Gift sample from India Sea food, Kerala, India.

Acrylicacid (Riedel) was extracted with an aqueous solution of $5 \% \mathrm{NaOH} / 20 \% \mathrm{NaCl}$ to remove the hydroquinone stabilizer. The monomer was distilled and the middle fraction were used Inhibitor free Acrylicacid (Fluka puriss) was also used.

Reagent-grade ceric ammonium supplied by Merck was used to prepare the initiator solution, and was used without further purification. Other reagents were of analytical grade and were used without further treatment.

\subsection{Graft Copolymerization}

The chitosan powder sample was dispersed in a definite volume was dissolved in $2 \%$ acetic acid, in a thermostated reaction flask for $60 \mathrm{~min}$. The ceric ammonium nitrate in $0.5 \mathrm{M}$ nitric acid solution was then loaded into the reactor under continuous stirring. Then a known weight of Acrylicacid was also injected into the reactor. The reaction was assumed to have started at the moment the monomer was injected.

Graft copolymerization was carried out at room temperature under constant stirring in nitrogen atmosphere for a particular time period. At the end of grafting copolymerization the reaction mixture was neutralized with a $1 \mathrm{M} \mathrm{NaOH}$ solution, and the reaction products (graft copolymer and homopolymer) were filtered and thoroughly washed with distilled water, and then dried to constant weight. The homopolymer was subsequently removed by extraction with $\mathrm{N}, \mathrm{N}$-dimethethyl formamide for $6 \mathrm{hrs}$. The remaining product, after drying to a constant weight, was considered to be a graft copolymer.

Grafting percentage $(\% \mathrm{G})$ which designates the amount of polymer grafted on the substract backbone (chitosan) and grafting efficiency $(\% \mathrm{E})$, which indicates the efficiency of conversion of the initial Acrylicacid to the grafted PAN, were calculated from the increase in weight of the chitosan after graft copolymerization in following manner.

$$
\begin{aligned}
& \% G=\frac{\left(w_{2}-w_{1}\right)}{w_{1}} \times 100 \\
& \% G=\frac{\left(w_{2}-w_{1}\right)}{w_{3}} \times 100
\end{aligned}
$$

\subsection{Evidence of Grafting}

It has been seen that the amidecarbonyl absorption band from grafted chains appears at $1649 \mathrm{~cm}^{-1}$. The band is located at $1670 \mathrm{~cm}^{-1}$ for acrylamide homopolymer. On the other hand, the most typical absorption bands of chitosan situated at $1558 \mathrm{~cm}^{-1}$ and $1661 \mathrm{~cm}^{-1}$ corresponding to amide-I and amide-II bands respectively, are not clearly visible since they are hidden by strong carbonyl absorption band of PAA in this spectrum region. However the CHI amide-I absorption can be observed as a shoulder at $1540 \mathrm{~cm}^{-1}$. The shift of the carbonyl absorption band of PAA amide-I band of chitosan to lower frequencies could be due to inter-and/or intramolecular interacting though hydrogen bonding. Naturally, the insolubility of PAA grafted CHI samples, inspite of containing a large number of amide groups, is produced by the cross linking (Figure 1).

\subsection{X-Ray Diffraction Studies}

The formation and quality of compounds were checked by X-ray diffraction (XRD) spectrum. The XRD pattern was measured by drop coated grafting compound on glass plate and employed with X-ray diffractometer (INEL X-ray diffractometer) of characteristic Co-k $\alpha 1$ radiation $(\lambda=1.78 \AA)$ in the range of $20^{\circ}$ to $90^{\circ}$ at a scan rate of $0.05^{\circ} / \mathrm{min}$ with the time constant of $2 \mathrm{~s}$.

\subsection{SEM Analysis of Grafting Compound}

Scanning Electron Microscopic (SEM) analysis was done using Hitachi S-4500 SEM machine. The sample were prepared on a carbon coated copper grid by just dropping a very small amount of the sample on the grid, extra solution was removed using a blotting paper and then the sample on the SEM grid were allowed to dry by putting it under a mercury lamp for $5 \mathrm{~min}$. 


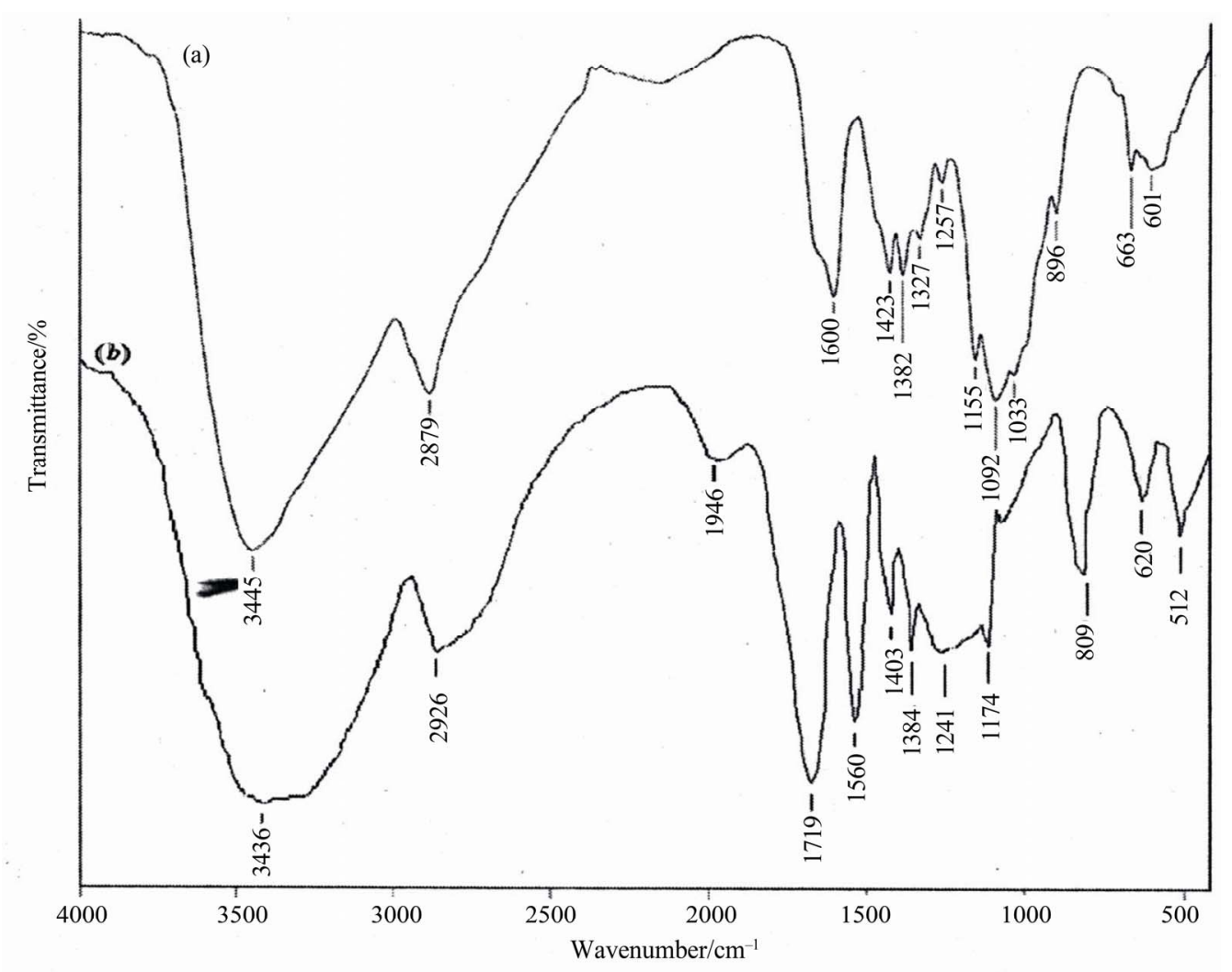

Figure 1. (a) FTIR spectra of pure chitosan; (b) FTIR spectra of grafted chitosan with acrylic acid (monomer).

\subsection{FTIR}

FTIR spectra were taken by using a Bruker IFS-28 instrument. The samples were prepared as $\mathrm{KBr}$ pellets.

\section{Antimicrobial Susceptibility Test}

The disc diffusion method was used to screen the antimicrobial activity. In vitro antimicrobial activity was screened by using Mueller Hinton Agar (MHA) obtained from Himedia (Mumbai). The MHA plates were prepared by pouring $15 \mathrm{ml}$ of molten media into sterile Petri plates. The plates were allowed to solidify for $5 \mathrm{~min}$ and $0.1 \%$ inoculum (0.5 McFarland standard) suspension was swabbed uniformly and the inoculum was allowed to dry for $5 \mathrm{~min}$. $50 \mu \mathrm{l}$ concentration of test sample was loaded on $0.5 \mathrm{~cm}$ sterile disc. The loaded disc was placed on the surface of medium and the compound was allowed to diffuse for $5 \mathrm{~min}$ and the plates were kept for incubation at $37^{\circ} \mathrm{C}$ for $24 \mathrm{~h}$. At the end of incubation, inhibition zones formed around the disc were measured with transparent ruler in millimeter. For each bacterial strain, negative controls were maintained where pure solvents were used instead of the extract. The control zones were subtracted from the test zones and the resulting zone diame- ter and the result obtained was tabulated and Ampicillin $(10 \mathrm{mcg} / \mathrm{disc})$ were used.

\section{Result and Discussion}

\subsection{Solubility Tests}

The solubility of PACN has been furnished in Table 1. It is evident that the grafted polymer are insoluble in many

Table 1. Results of solubility tests on $\mathbf{4 5 \%}$ grafted chitosan.

\begin{tabular}{cc}
\hline Solvent & Observation \\
\hline Ethanol & Soluble \\
Acetic acid & Insoluble \\
Glacial acetic acid:ethanol $(1: 1)$ & Cloudiness \\
Glacial acetic acid:ethanol $(1: 2)$ & swelling \\
DMF & swelling \\
DMSO & Insoluble \\
THF & Insoluble \\
Distilled water & Insoluble \\
\hline
\end{tabular}


protic and aprotic solvents. This behaviour may be attributed to a slight crosslinking at higher grafting yields. Although PNVI is soluble in organic solvents such as ethanol, DMF, DMSO and THF, grafted chitosans were found to be insoluble in these solvents. This shows that chitosan's nature is predominant over PACN in these solvents for samples studied.

\subsection{The Effect of Initiator Concentration}

Table 2 shows the effect of the concentration of the initiator $\mathrm{Ce}^{4+}$ on grafting of Acrylicacid. It was observed that the miximum percentage of grafting occurred at 5.70 $\times 10^{-3} \mathrm{M}$. A further increase in the $\mathrm{Ce}^{4+}$ concentration leads to a decrease in the grafting percentage of Acrylicacid. This could be explained by the fact that ceric ion at a higher concentration causes the termination of grafting polymeric chain growth since ceric ion is a very good terminator ( ). Another factor which could contribute to a decrease in the grafting percentage at higher concentration of initiator is the increase the homopolymer formation, which competes with the grafting reaction for the available monomer.

\subsection{The Effect of Monomer Concentration}

The effect of the Acrylicacid concentration on the graft yield obtained with chitosan is shown in Table 3. An increase in the monomer concentration is accompanied by significant increase in grafting up to $0.75 \mathrm{M}$. However with the further increase in the concentration of monomer, grafting is found decrees. This could be ascribed to the substantial amount of polymer grafted on the substract backbone, which inhibit the diffusion of $\mathrm{Ce}^{4+}$ and the monomer into chitosan for further grafting.

\subsection{The Effect of Tempertaure}

The dependence of grafting yield on temperature in the range of $25^{\circ} \mathrm{C}-52^{\circ} \mathrm{C}$ is shown in Table 4 . The maximum grafting of Acrylicacid occurs at $35^{\circ} \mathrm{C}$ within $180 \mathrm{~min}$. A further increase in temperature reduces the percentage grafting. This is to be expected since at higher temperature various chain transform reaction are accelerated which leads to a decrease in the percentage of grafting on in other words the formation of more homopolymer.

Table 2. The effect of redox initiator concentration on the grafting of Acrylicacid onto chitosan.

\begin{tabular}{ccccc}
\hline No & Chitosan $(\mathrm{g})$ & $\mathrm{Ce}^{4+} \times 10^{3}(\mathrm{M})$ & $\% \mathrm{G}$ & $\% \mathrm{E}$ \\
\hline 1 & 5.03 & 3.90 & 55.6 & 36.9 \\
2 & 5.07 & 5.70 & 106.3 & 76.1 \\
3 & 5.07 & 7.88 & 53.07 & 35.2 \\
4 & 3.00 & 9.50 & 44.4 & 26.6 \\
\hline
\end{tabular}

Acryonitrile $6.00 \mathrm{~g}$, temperature of $25^{\circ} \mathrm{C}$ reaction time of $180 \mathrm{~min}$.

\subsection{The Effect Time}

The effect of the reaction time on the percentage of grafting and grafting efficiency is shown in Table 5. The percentage of grafting was found to increase linearly with time and then approximately constant. The initial increase in the rate due to the increase in the number of grafting site, but this number remain constant with further increase of time.

The following mechanism has been suggested for the graft copolymerization of Acrylicacid onto chitosan.

Table 3. The effect of monomer concentration on the grafting of Acrylicacid onto chitosan.

\begin{tabular}{|c|c|c|c|c|}
\hline No. & Chitosan (g) & Acrylicacid (Mol/L) & $\% \mathrm{G}$ & $\% \mathrm{E}$ \\
\hline 1 & 2.00 & 0.5 & 11.0 & 12 \\
\hline 2 & 2.00 & 1.00 & 33.0 & 31 \\
\hline 3 & 2.00 & 2.00 & 69.3 & 68 \\
\hline 4 & 2.00 & 3.00 & 10.5 & 7 \\
\hline
\end{tabular}

Table 4. The effect of temperature on grafting of acrylicacid onto chitosan.

\begin{tabular}{ccccc}
\hline No. & Chitosan (g) & Temperature $\left({ }^{\circ} \mathbf{C}\right)$ & \% G & \% E \\
\hline 1 & 2.10 & 25 & 10 & 7 \\
2 & 2.04 & 35 & 54 & 36 \\
3 & 2.04 & 40 & 24 & 22 \\
4 & 2.05 & 50 & 13 & 11 \\
\hline
\end{tabular}

$\mathrm{Ce}^{4+}=30.9 \times 10^{-3} \mathrm{M}$, temperature of $25^{\circ} \mathrm{C}$ reaction time of $180 \mathrm{~min}$.

Table 5. The effect of time on the grafting of acrylicacid onto chitosan.

\begin{tabular}{cccc}
\hline Time $(\min )$ & $\% \mathrm{G}$ & $\% \mathrm{E}$ & \\
\hline 30 & 12 & 11 & \\
60 & 33 & 22 & \\
90 & 38 & 26 & - \\
150 & 42 & 25 & - \\
\hline
\end{tabular}

$\mathrm{Ce}^{4+}=30.9 \times 10^{-3} \mathrm{M}$, chitosan $2.00 \mathrm{~g}$, acryolonitrile $=3.00 \mathrm{~g}$ temperature of $25^{\circ} \mathrm{C}$. 
Production of Free Radical: Oxidation.

$\mathrm{CS}+\mathrm{Ce}^{4+} \rightarrow$ Complex $\rightarrow \mathrm{CS}+\mathrm{Ce}^{3+}+\mathrm{H}^{+}$

\section{Initiation}

$\mathrm{CS}+\mathrm{M} \rightarrow \mathrm{CSM}$

$\mathrm{Ce}^{4+}+\mathrm{M}$ Compex $\mathrm{M}+\mathrm{Ce}^{3+}+\mathrm{H}^{+}$

\section{Propagation}

$\mathrm{CS} \mathrm{M}+\mathrm{M} \rightarrow \mathrm{CSM}_{1}$

$\mathrm{CSM}_{1}+\mathrm{nM} \rightarrow \mathrm{CS}(\mathrm{M})_{\mathrm{n}+1}$

$\mathrm{M}^{+}+\mathrm{nM} \rightarrow(\mathrm{M})_{\mathrm{n}+1}$

\section{Termination}

$\mathrm{CS}(\mathrm{M})_{\mathrm{n}+1}+\mathrm{Ce} \rightarrow \mathrm{CS}(\mathrm{M})_{\mathrm{n}+1}+\mathrm{Ce}^{3+}$

(Graft Copolymer)

$(\mathrm{M})_{\mathrm{n}+1}+\mathrm{Ce}^{4+} \rightarrow(\mathrm{M})_{\mathrm{n}+1}+\mathrm{Ce}^{3+}$

(Homopolymer) Chain Transfer

$$
\begin{aligned}
& \mathrm{CSMn}+\mathrm{Ce}^{4+} \rightarrow \mathrm{CS} \mathrm{Mn}+\mathrm{Ce}^{3+}+\mathrm{H}^{+} \\
& \mathrm{CS} \mathrm{Mn}+\mathrm{M} \rightarrow \mathrm{CS} \mathrm{Mn}+\mathrm{M} .
\end{aligned}
$$

where $\mathrm{CH}, \mathrm{m}, \mathrm{CH}(\mathrm{M})_{\mathrm{n}+1}$ and $(\mathrm{M})_{\mathrm{n}+1}$ represent chitosan Acrylicacid, the graftcopolymer and homopolymer, respectvilly.

\section{X-Ray Diffraction Studies}

The grafting was also supported by XRD (Figure 2). The $\mathrm{X}$-ray diffraction spectra of the grafted chitosan show many crystalline areas between $2 \theta 20^{\circ}-32^{\circ}$ and $38^{\circ}-$ $45^{\circ}$ (due to polyAcrylicacid grafts at the chitosan backbone), while no such peaks are visible in the XRD of the chitosan itself.

\subsection{SEM}

Figure 3 shows the SEM micrographs of chitosan 1) and chitosan/PAA (Acrylic Acid) 2) blend. It provides direct evidence that phase separation occurred in chitosan/PAA (Acrylic Acid) blend. This sample has a distinct twophase morphology, i.e., a continuous PAA (Acrylic Acid) phase with a dispersed chitosan phase indicates poor interfacial adhesion between terpolyamide and chitosan phases. It is well known that chitosan has the good ability of degradation. Therefore, PAA (Acrylic Acid) interfered with chitosan can improve its biodegradability.

\subsection{TGA Studies}

The TGA of pure chitosan and chitosan-g-AA (Acrylic Acid) is given in Figure 4.

The grafting was also supported by thermogravimetric

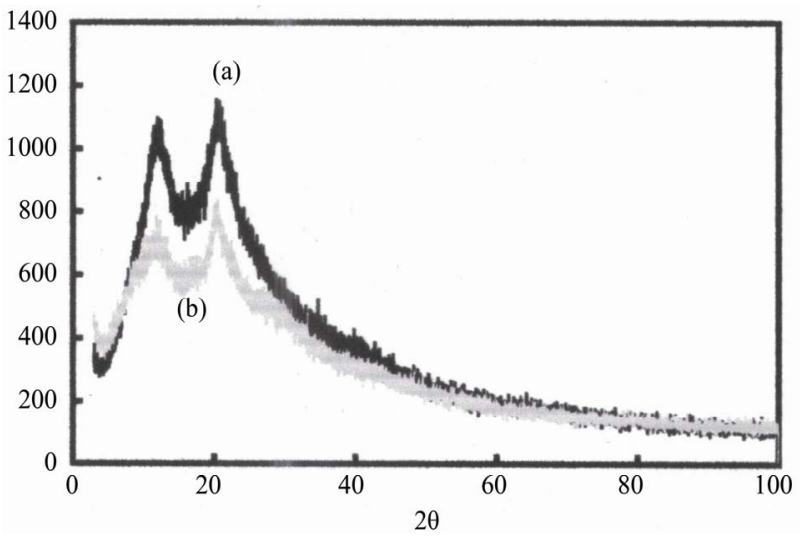

Figure 2. (a) XRD of pure chitosan; (b) chitosan-g-AA (Acrylic acid) graft copolymer.

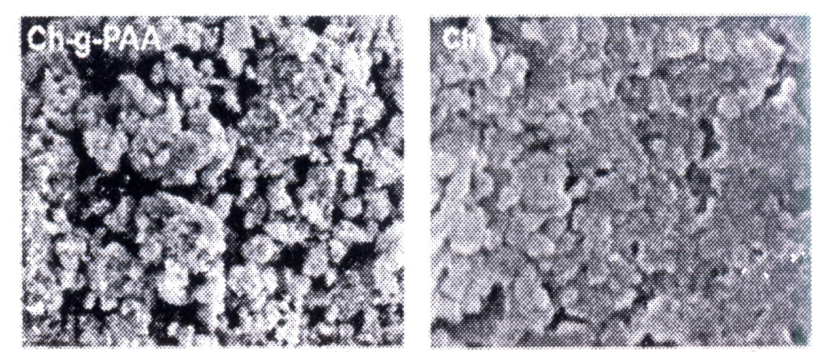

Figure 3. SEM picture of grafted chitosan.

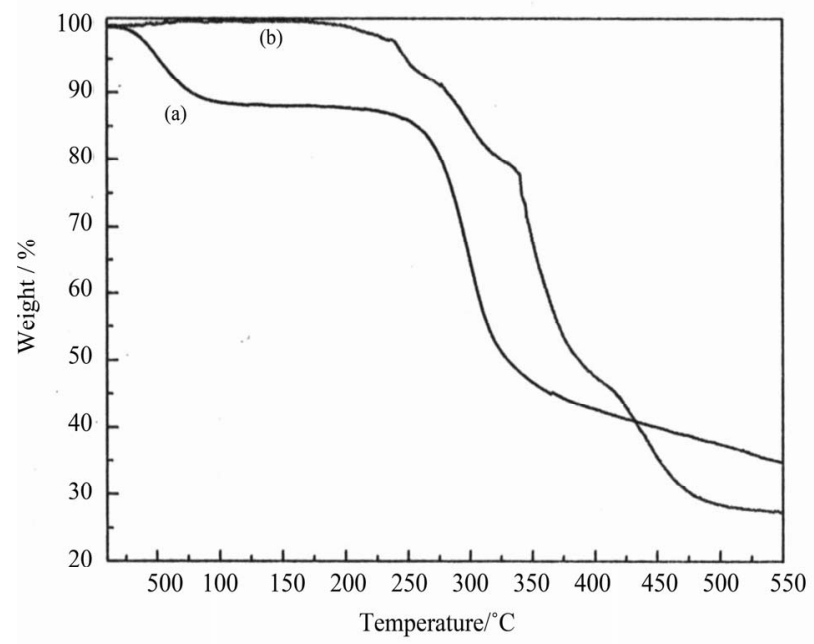

Figure 4. (a) TGA of chitosan; (b) TGA of chitosan-g-AA (Acrylic Acid) graft copolymer.

analysis (Figure 4). TGA of chitosan (a) shows a weight loss in two stages. The first stage ranges between 10 and $100^{\circ} \mathrm{C}$ and shows about $12 \%$ loss in weight. This may correspond to the loss of adsorbed and bound water. The second stage of weight loss starts at $210^{\circ} \mathrm{C}$ and continues up to $360^{\circ} \mathrm{C}$ during which there was $44 \%$ weight loss due to the degradation of chitosan. However, the TGA of the 
grafted product is different. The latter has three stage of weight loss between $10^{\circ} \mathrm{C}$ and $550^{\circ} \mathrm{C}$. The first stage of weight loss starts at $180^{\circ} \mathrm{C}$ and continues up to $340^{\circ} \mathrm{C}$, during which there was $22 \%$ weight loss due to the degradation of chitosan. The second stage from $340^{\circ} \mathrm{C}$ to $420^{\circ} \mathrm{C}$ and the third stage from $420^{\circ} \mathrm{C}$ to $500^{\circ} \mathrm{C}$ may contribute to the decomposition of different structure of the graft co-polymer. Below $430^{\circ} \mathrm{C}$ the copolymer had lower weight loss than chitosan. These mean that the grafting of chitosan increases the thermal stability of chitosan in some extent.

\section{Antibacterial Activity of Graft Copolymerized of Acrylicacid on Chitosan}

A preliminary study has been carried out to compare the antibacterial activity of grafted chitosan hydrochloride film samples with that of chitosan. The study was carried out against $P$. aeruginosa, E. coli, B. subtilis and $S$. aureus using the inhibition zone method. The results are shown in Table 3. It was observed that grafting of NVI improved the antibacterial activity of chitosans. While the inhibition zone diameter for chitosan film ranged between 9 and $11 \mathrm{~mm}$ against indicated bacteria, the inhibition zone increased up to $17 \mathrm{~mm}$ (against B. subtilis) by grafting. Although the difference is not significant, activity of gram-positive bacteria seems to be more pronounced; increase in the inhibition zone diameter is 4 - 5 $\mathrm{mm}$ in gram-negative ones whereas it is $5-7 \mathrm{~mm}$ in gram-positive ones. Grafted samples showed an increasing antibacterial activity as the degree of grafting increased for all of gram-negative and gram positive bacterias; a minimum of $2 \mathrm{~mm}$ increase was observed consistently when the grafting percentage increased from $82.5 \%$ to $145 \%$. Average film weight (thickness) also effected the degree of antimicrobial activity of both chitosan and grafted chitosan samples. And 3 - $4 \mathrm{~mm}$ increase was observed when the average film weight was increased from 134 to 296.

Table 6. Antifungal activities of GRAFTING compounds minimal inhibitory concentration (MIC) $\mathrm{mg} / \mathrm{ml}$.

\begin{tabular}{cc}
\hline Fungus & MIC $(\mathrm{mg} / \mathrm{ml})$ \\
\hline C. albicans & $15.22 \pm 0.04$ \\
C. tropicalis & $17.32 \pm 0.07$ \\
C. krusei & $20.28 \pm 0.00$ \\
C. Kefyr & $11.33 \pm 0.44$ \\
A. flavus & $18.63 \pm 0.64$ \\
\hline
\end{tabular}

\section{Antifungal Activity}

Further the grafting compound were found to be highly toxic against clinically isolated fungal species. At a concentration of $50 \mu \mathrm{l}$ grafting compound revealed a higher antifungal activity against C. albicans, Candida kefyr, Aspergillus niger whereas intermediated activity were showed against C. tropicalis, C. krusei, A. flavus, A. fumigatus. The inhibitory activities of all the grafting compound are reported in Table 6. The data results were compared with the standard antimicrobics of Ketoconazole $(30 \mathrm{mg})$ and Itraconazole $(30 \mathrm{mg})$.

\section{Conclusions}

The grafting of acrylicacid onto chitosan, in the absence of N,N-methylenebisacrylamide as crosslinking agent, leads to slightly soluble products. When N,Nmethylenebisacrylamide was used as crosslinker insoluble grafted chitosan was obtained which could be easily separated from the reaction medium and purified. Moreover, the insoluble grafted chitosan showed characteristics of SEM, XRD and FTIR. This study has demonstrated that grafting compound showed a higher antibacterial and fungal activity. Grafting compound markedly inhibited the growth of most bacteria and fungal tested although their inhibitory effects differed.

\section{Acknowledgements}

This work was supported by Bio-Lab (A-41, Janpath, Ashok Nagar, Bhubaneswar, India-751009).

\section{REFERENCES}

[1] P. L. Nayak, "Grafting of Vinyl Monomers onto Wool Fibers," Journal of Macromolecular Science-Reviews in Macromolecular Chemistry \& Physics, Vol. 14, No. 2, 1996, pp. 193-213.

[2] P. L. Nayak, "Grafting of Vinyl Monomers onto Nylon," Journal of Macromolecular Science-Reviews in Macromolecular Chemistry \& Physics, Vol. 17, No. 2, 1979, pp. 149-267.

[3] P. L. Nayak, "Vinyl and Graft Copolymerization Initiated by Potassium Peroxydiphosphate," Journal of Macromolecular Science-Reviews in Macromolecular Chemistry \& Physics, Vol. 25, No. 2, 1985, pp. 157-189.

[4] P. L. Nayak, S. Lenka and N. C. Pati, "Grafting Vinyl Monomers onto Wool Fibers:I:Garfting Copolymerization of Methyl Methacrylate onto Wool Using V(v)Thiourea Redox System," Journal of Applied Polymer Science, Vol. 22, No. 11, 1978, pp. 3301-3309. doi:10.1002/app.1978.070221124

[5] P. L. Nayak, R. K. Samal and M. C. Nayak, "Garfting of Vinyl Monomers onto Nylon-6:I:Graft Co-Polymerizetion of Acryl Amide onto Nylon-6Mn(III) as Initiator Angew," 
Macromolecular Chemistry and Physics, Vol. 13, No. 2, 1979, pp. 261-271. doi:10.1080/00222337908066601

[6] P. L. Nayak, M. K. Mishra and A. K. Tripathy, "Grafting Vinyl Monomer onto Polyster Fibres:I:Graft Copolymerization of Methyl Methacrylate onto PET Using Hexavalent Chromium," Journal of Applied Polymer Science, Vol. 26, No. 6, 1981, pp. 2109-2111. doi:10.1002/app.1981.070260634

[7] A. K. Pradhan, N. C. Pati and P. L. Nayak, "Grafting Vinyl Monomers onto Polyster Fibers:III:Graft Copolymerization of Methyl Methaacrylate onto PET Using $\mathrm{KMnO}_{4}$-Oxalic Acid Redox System," Journal of Applied Polymer Science, Vol. 27, No. 6, 1982, pp. 2131-2138. doi:10.1002/app.1982.070270624

[8] S. Lenka and P. L. Nayak, "Grafting of Vinyl Monomers onto Polyster Fibers:IV: Graft Copolymerization of Ethyl Methacrylate on PET Using Acetylacetonate Complex of Mn(III), Co(III) and Fe(III)," Journal of Applied Polymer Science, Vol. 19, 1982, p. 987.

[9] S. Lenka, P. L. Nayak and M. R. Dash, "Photo Induced Graft Copolymerization:VI:Graft Copolymerization of Methyl Methacrylate onto Cellulose in Presence of Pyridine-Bromine Charge-Transfer Complex as Initiator," In: S. lenka, P. L. Nayak and M. R. Dash, Eds., Polym, Photochemistry, Vol. 3, 1983, p. 109.

[10] S. Sasmal, G. Sahu and P. L. Nayak, "Grafting Vinyl Monomers onto Chemically Modified Wool Fibres: XI: Graft Copolymerization of Methyl Methacrylate onto Reduced Wool Fiber Using Acetylacetonate Complex of Manganese (III)," Journal of Macromolecular Science, Vol. 20, No. 2, 1983, pp. 153-167. doi:10.1080/00222338308069956

[11] P. L. Nayak, S. Lenka and A. P. Das, "Grafting of Vinyl Monomers onto Natural Rubber: V: Graft Copolymerization of Methyl Methacrylate onto Natural Rubber Using Pottasium Peroxydisulphate," Journal of Polymer Science Part A: Polymer Chemistry, Vol. 30, No. 7, 1985, pp. 2753- 2759.

[12] P. L. Nayak, "Photo Induced Graft Copolymerzation onto selected Fibers," Journal of Macromolecular Science-Reviews in Macromolecular Chemistry \& Physics, Vol. 31, No. 1, 1991, pp. 91-116.

[13] P. L. Nayak, S. Lenka and N. C. Pati, "Grafting Vinyl Monomers onto Silk Fibers V: Graft Copolymerization of Methyl Methacrylate onto Sil Fibers Using Potassium Permanganate as Intiator," Journal of Macromolecular Science, Vol. 13, 1979, pp. 1157-1169. doi:10.1080/00222337908056707

[14] P. L. Nayak, N. C. Pati and A. K. Pradhan, "Grafting Vinyl Monomers onto Nylon-6:III:Graft Copolymerization of Methyl Methacrylate on Nylon-6 Using Fe(III)Thiourea Redox System," Journal of Polymer SciencePolymer Chemistry Edition, Vol. 19, No. 3, 1981, pp. 831834. doi:10.1002/pol.1981.170190321

[15] P. L. Nayak and S. Lenka, "Photo-Induced Graft Copolymerization IV: Photo Induced Graft Coploymerization of Methyl Methacrylate Using N-Bromo Succinamide as the
Initiator," Journal of Applied Polymer Science, Vol. 27, 1982, p. 3625.

[16] P. L. Nayak and S. Lenka, "Grafting Vinyl Monomers onto CelluloseII:Graft-Copolymerization of Methyl Methacrylate onto Cellulose Using V(V)-Thiourea Redox System," Journal of Polymer Science-Polymer Chemistry Edition, Vol. 19, 1981, p. 1561.

[17] D. Sahoo, S. Sahoo, P. Mohanty, S. Sasmal and P. L. Nayak, "Chitosan: A New Versatile Bio-Polymer for Various Applications," Designed Monomers and Polymers, Vol. 12, No. 5, 2009, pp. 377-404. doi:10.1163/138577209X12486896623418

[18] M. N. V. Ravi Kumar, R. A. A. Muzzarelli, C. Muzzarelli, H. Sashiwa and A. J. Domb, "Synthesis of a Chitosan-Dendrimer Hybrid and Its Biodegradation," Chemical Reviews, Vol. 104, No. 12, 2004, pp. 6017-6084.

[19] M. N. V. R. Kumar, "Grafting Vinyl Monomers onto Natural and Synthetic Polymers," Reactive and Functional Polymers, Vol. 46, No. 1, 2000, pp. 1-27.

[20] O. Felt, P. Buri and R. Gurny, "Thiolated Chitosans: Novel Polymers for Mucoadhesive," Drug Delivery and Industrial Pharmaceuticals, Vol. 24, No. 4, 1998, pp. 979-993. doi:10.3109/03639049809089942

[21] S. Hirano, H. Seino, I. Akiyama and I. Nonaka, "Chitin Nanowhisker and Chitosan Nanoparticles in Protein Immobilization for Biosensor," Applications Polymer Engineering Science, Vol. 59, 1989, pp. 897-901.

[22] P. A. Sanford, G. Skjak-Braek, T. Anthonsen and P. A. Sanford, Eds., "Chitin and Chitosan-Sources, Chemistry, Biochemistry, Physical Properties and Applications," Elsevier, London, 1989, pp. 51-70.

[23] R. A. A. Muzzarelli, "Human Enzymatic Activities Related to the Therapeutical Administration of Chitin Derivatives," Cell Molecular and Life Science, Vol. 53, No. 1, 1997, pp. 131-140. doi:10.1007/PL00000584

[24] O. Felt, P. Buri and R. Gurny, "Chitosan: A Unique Polysaccharide for Drug Delivery," Drug Delivery and Industrial Pharmaceuticals, Vol. 24, No. 4, 1998, pp. 979-993.

[25] P. C. Bersch, B. Nies and A. Liebendorfer, "Graft Copolymerized Chitosan-Present Status and Applications," Journal of Material Science, Materials in Medicine, Vol. 6, No. 2, 1995, pp. 231-240. doi:10.3109/03639049809089942

[26] M. Sugimoto, M. Morimoto and H. Sashiwa, "Synthesis and Bioactivities of Poly (Ethylene Glycol)-Chitosan Hybrids," Carbohydrate Polymers, Vol. 36, No. 1, 1998, pp. 49-59. doi:10.1016/S0144-8617(97)00235-X

[27] K. Kurita, T. Kojima, T. Munakata, H. Akao, T. Mori, Y. Nishiyama, et al., "Preparation of Nonnatural Branched Chitin and Chitosan," Chemistry Letters, Vol. 27, No. 4, 1998, pp. 317-318. doi:10.1246/cl.1998.317

[28] H. Sashiwa and Y. Shigemasa, "Chitosan, a Biodegradable and Biocompatible Polymer," Carbohydrate Polymers, Vol. 39, No. 2, 1999, pp. 127-138. doi:10.1016/S0144-8617(98)00167-2 
[29] N. Terada, M. Morimoto, H. Saimoto, Y. Okamato, S. Minami and Y. Shigemasa, "Graft Copolymerized Chitosan-Present Status and Applications," Chemistry Letters, Vol. 28, No. 12, 1999, pp. 1285-1286. doi:10.1246/cl.1999.1285

[30] V. Alexandrova, G. V. Obukhova, N. S. Dominina and D. A. Topchiev, "Modification of Chitosan for Construction of Efficient Antioxidant Biodegradable Macromolecular Systems," Macromolecular Symposia, Vol. 144, No. 2, 1999, pp. 413-418. doi:10.1002/masy.19991440138

[31] T. R. Sridhari and P. K. Dutta, "Ceric Ammonium Nitrate Induced Grafting of Polyacrylamide onto Chitosan," Indian Journal of Chemical Technology, Vol. 7, No. 1, 2000, pp. 198-204.

[32] A. Heras, N. M. Rodriguez and V. M. Ramos, "N-methylene. Phosphonic Chitosan: A Novel Soluble Derivative," Carbohydrate Polymers, Vol. 44, No. 1, 2001, pp. 1-8. doi:10.1016/S0144-8617(00)00195-8

[33] Y. C. Wang, M. C. Lin, D. M. Wang and H. J. Hsieh, "Fabrication of a Novel Porous PGA-Chitosan Hybrid Matrix for Tissue Engineering," Biomaterials, Vol. 24, No. 6, 2003, pp. 1047-1057. doi:10.1016/S0142-9612(02)00434-9

[34] Z. K. Yang and Y. Yuan, "Ceric Ammonium Nitrate Induced Grafting of Polyacrylamide onto," Journal of Applied Polymer Science, Vol. 82, No. 8, 2001, pp. 18381843. doi:10.1002/app.2026

[35] S. Chen and Y. Wang, "Study on $\beta$-Cyclodextrin Grafting with Chitosan and Slow Release of Its Inclusion Complex with Radioactive Iodine," Journal of Applied Polymer Science, Vol. 82, No. 10, 2001, pp. 2414-2421. doi:10.1002/app.2092

[36] B. O. Jung, C. H. Kim, K. S. Choi, Y. M. Lee and J. J. Kim, "Results, Phosphorous Containing Chitosan Beads for Controlled Oral Drug," Journal of Applied Polymer Science, Vol. 72, No. 13, 1999, pp. 1713-1719. doi:10.1002/(SICI)1097-4628(19990624)72:13<1713::AI D-APP7>3.0.CO;2-T

[37] A. R. Kotze, H. L. Lueben, B. J. De Leeuw, A. G. De Boer, J. C. Verhoef and H. E. Junginger, "Synthesis of Novel Chitosan Derivatives for Micellar Solubilization of Chitosan," Pharmaceutical Research, Vol. 14, No. 9, 1997, pp. 1197-1202. doi:10.1023/A:1012106907708

[38] M. Thanou, J. C. Verhoef and H. E. Junginger, "Morden Drug Delivery Application of Chitosan," Advanced Drug Delivery Reviews, Vol. 52, No. 2, 2001, pp. 117-126. doi:10.1016/S0169-409X(01)00231-9

[39] A. S. Hoffman, G. Chen, X. Wu, Z. Ding, B. Kabra, K.
Randeri, et al., "Design and Evaluation of Mucoadhesive Controlled Release Oral Tablets of Terbutaline Sulphate using some Natural Materials," Polymer Preparations, Vol. 38, No. 2, 1997, pp. 524-525.

[40] R. A. Tasker, B. J. Connell, S. J. Ross and C. M. Elson, "Reduction of Postoperative Adhesions by N,O-Carboxymethylchitosan and Spermine NONOate in Rats," Laboratory Animals, Vol. 32, No. 2, 1998, pp. 270-275. doi: $10.1258 / 002367798780559220$

[41] D. K. Singh and A. R. Ray, "Study on Radiation-Induced Grafting of Styrene onto Chitin and Chitosan," Carbohydrate Polymers, Vol. 36, No. 2-3, 1998, pp. 251-255. doi:10.1016/S0144-8617(97)00260-9

[42] J. K. F. Suh and H. W. T. Matthew, "Chitosan-Based Hyaluronic Acid Hybrid Polymer Fibers as a Scaffold Biomaterial for Cartilage Tissue Engineering," Biomaterials, Vol. 21, No. 24, 2000, pp. 2589-2598.

[43] M. N. V. R. Kumar, R. A. A. Muzzarelli, C. Muzzarelli, H. Sashiwa and A. J. Domb, "Chemical Modification of Chitosan: Preparation and Lectin Binding Properties of $\alpha$-Galactosyl-Chitosan Conjugates. Potential Inhibitors in Acute Rejection Following Xenotransplantation," Chemical Reviews, Vol. 104, No. 12, 2004, pp. 6017-6084. doi:10.1021/cr030441b

[44] J. Berger, M. Reist, J. M. Mayer, O. Belt and R. Gurny, "Fabric Structure Influence in the Deposition of Flavour Microcapsules," European Journal of Pharamaceutics and Biopharmaceutics, Vol. 57, No. 1, 2004, pp. 35-52. doi:10.1016/S0939-6411(03)00160-7

[45] S. Senel and S. J. McClure, "Potential Applications of Chitosan in Veterinary Medicine," Advanced Drug Delivery Reviews, Vol. 56, No. 10, 2004, pp. 1467-1480. doi:10.1016/j.addr.2004.02.007

[46] A. J. Verma, S. V. Deshpande and J. K. Kennedy, "Graft Copolymerization of Vinyl Monomers onto Chitosan," Carbohydrate Polymers, Vol. 55, No. 1, 2004, pp. 77-93.

[47] E. Guibal, "Chemical and Radiation Induced Grafting of Indole onto Chitin," Separation and Purification Technology, Vol. 38, No. 1, 2004, pp. 43-74. doi:10.1016/j.seppur.2003.10.004

[48] K. Kurita, "Perspectives of Chitin and Chitosan Nanofibrous Scaffolds in Tissue," Progress in Polymer Science, Vol. 26, No. 9, 2001, pp. 1921-1971. doi:10.1016/S0079-6700(01)00007-7

[49] M. Prabaharan and J. F. Mano, "Preparation of Chitosan Scaffolds for Tissue Engineering," Drug Delivery, Vol. 12, No. 1, 2005, pp. 41-57. doi:10.1080/10717540590889781 